\title{
In vitro degradation of dermal sheep collagen cross-linked using a water- soluble carbodiimide
}

\author{
L.H.H. Olde Damink, P.J. Dijkstra, M.J.A. van Luyn*, \\ P.B. van Wachem* ${ }^{*}$ P. Nieuwenhuis* and J. Feijen \\ Department of Chemical Technology and Institute for Biomedical Technology, University of Twente, P.O. Box 217, \\ 7500 AE Enschede, The Netherlands; "Department of Histology and Cell Biology, University of Groningen, \\ Oostersingel 69/2, 9713 EZ Groningen, The Netherlands
}

\begin{abstract}
Bacterial collagenase was used to study the susceptibility of dermal sheep collagen (DSC) crosslinked with a mixture of the water-solubie carbodiimide 1-ethyl-3-(3-dimethyi aminopropyl)carbodiimide hydrochloride and $N$-hydroxysuccinimide (E/N-DSC) towards enzymatic degradation. Contrary to non-cross-linked DSC (N-DSC), which had a rate of weight-loss of $18.1 \%$ per hour upon degradation, no weight loss was observed for E/N-DSC during a $24 \mathrm{~h}$ degradation period. The tensile strength of the E/N-DSC samples decreased during this time period, resulting in partially degraded samples having $80 \%$ of the initial tensile strength remaining. The susceptibility of E/N-DSC samples towards enzymatic degradation could be controlled by varying the degree of cross-linking of the samples. Ethylene oxide sterilization of E/N-DSC samples made the material more resistant against degradation compared with non-sterilized E/N-DSC samples. This may be explained by a decrease of the adsorption of bacterial collagenase onto the collagen owing to reaction of ethylene oxide with remaining free amine groups in the collagen matrix.
\end{abstract}

Keywords: Collagen, cross-linking, carbodiimide, degradation, collagenase

Received 16 March 1995; accepted 15 June 1995

Cross-linking of collagen-based biomaterials is often necessary to improve the resistance against enzymatic degradation. Currently, several methods are available for the cross-linking of collagen-based biomaterials. Glutaraldehyde is the most commonly used bifunctional reagent ${ }^{1}$. Hexamethylene diisocyanate can also be used for the cross-linking of collagen ${ }^{2}$. However, the use of these reagents in the cross-linking of collagen may result in the release of toxic products both in vitro ${ }^{3-5}$ and in vivo ${ }^{6,7}$. A new class of crosslinking agents for collagen more recently described are the polyepoxy compounds ${ }^{8,9}$.

The cross-linking of dermal sheep collagen (DSC) using a mixture of the water-soluble carbodiimide 1 ethyl-3-(3-dimethyl aminopropyl)carbodiimide hydrochloride (EDC) and $N$-hydroxysuccinimide (NHS) has been described in the foregoing paper ${ }^{10}$. Cross-linking of DSC was performed by activation of the carboxylic acid groups of DSC through their succinimate esters followed by reaction with an amine group. The resulting materials ( $\mathrm{E} / \mathrm{N}$-DSC) had a higher shrinkage temperature $\left(T_{s}\right)$ compared with glutaraldehyde cross-linked DSC, which shows that cross-linking using a mixture of EDC and NHS is a good alternative for glutaraldehyde cross-linking.

Correspondence to Professor Dr J. Feijen.
Here we report on the in vitro degradation behaviour of E/N-DSC using bacterial collagenase as the degrading enzyme. Previously, ethylene oxide gas sterilization was selected as the preferred sterilization method for collagen-based biomaterials ${ }^{11}$. Therefore, the influence of ethylene oxide sterilization on the in vitro degradation behaviour of E/N-DSC was also studied.

\section{MATERIALS AND METHODS}

\section{Cross-linking of dermal sheep collagen}

Dermal sheep collagen (DSC) was obtained from the Zuid-Nederlandse Zeemlederfabriek (Oosterhout, The Netherlands) and prepared as reported previously ${ }^{12}$. The fibrous collagen network was washed four times with water, twice with acetone and twice with water, and was subsequently frozen and lyophilized to give non-cross-linked dermal sheep collagen (N-DSC).

Cross-linking of DSC with EDC and NHS (E/N-DSC) was performed by immersing N-DSC samples weighing $1 \mathrm{~g}$ (1.2 mmol carboxylic acid groups) in $50 \mathrm{ml}$ water containing $1.15 \mathrm{~g} \quad(6.0 \mathrm{mmol})$ EDC (z.S., MerckSchuchardt, Hohenbrun, Germany) and $0.28 \mathrm{~g}$ (2.4 mmol) NHS (z.S., Merck-Schuchardt) for $2 \mathrm{~h}$ at room temperature to give $\mathrm{E} / \mathrm{N}-\mathrm{DSC}^{10}$. During cross- 
linking, the $\mathrm{pH}$ of the solution was maintained at 5.5 using a $\mathrm{pH}$ stat apparatus (702 SM Titrino, Metrohm, Herisau, Switzerland). After cross-linking, the E/NDSC samples were washed with a $0.1 \mathrm{M} \mathrm{Na}_{2} \mathrm{HPO}_{4}$ solution for $2 \mathrm{~h}$ to hydrolyse any remaining NHSactivated carboxylic acid groups. Subsequently, the examples were washed four times with distilled water and lyophilized.

E/N-DSC samples with different degrees of crosslinking were obtained using molar ratios of EDC to NHS to COOH of 0.2:0.08:1, 0.5:0.2:1, 1:0.4:1 and 5:2:1, respectively. All samples were cross-linked at $\mathrm{pH} 5.5$ for $2 \mathrm{~h}$.

\section{Ethylene oxide sterilization}

E/N-DSC samples were air dried before sterilization with ethylene oxide gas. Sterilization was performed by exposing the samples to a $100 \%$ ethylene oxide atmosphere at a relative humidity of $70 \%$ for $5 \mathrm{~h}$ at $55^{\circ} \mathrm{C}^{11}$. After sterilization, the samples were aerated with a warm air flow at atmospheric pressure for at lcast $48 \mathrm{~h}$ to romove ethylono oxide from the DSC matrix before use in further experiments.

\section{Characterization}

The degree of cross-linking of DSC samples crosslinked with either a mixture of EDC and NHS was related to the increase in shrinkage temperature ${ }^{13}$. Shrinkage temperatures $\left(T_{\mathrm{s}}\right)$ of cross-linked or noncross-linked DSC samples immersed in water were determined as described previously ${ }^{1}$. The free amine group content of the samples was determined spectrophotometrically after reaction of the primary amine groups with 2,4,6-trinitrobenzenesulphonic acid $^{1}$ and is expressed as the number of amine groups present per 1000 amino acids ( $n$ per 1000).

\section{Mechanical properties}

Stress-strain curves of non-cross-linked and crosslinked DSC samples fully hydrated in phosphatebuffered saline $\left(0.14 \mathrm{M} \mathrm{NaCl}, 0.01 \mathrm{M} \mathrm{Na}_{2} \mathrm{HPO}_{4}, 0.002 \mathrm{M}\right.$ $\mathrm{NaH}_{2} \mathrm{PO}_{4}, \mathrm{pH}$ 7.4, NPBI, Emmercompascuum, The Netherlands) were determined by uniaxial measurements using an Instron mechanical tester ${ }^{1}$. The tensile strength, the elongation at alignment, the elongation at break, the low strain modulus and the high strain modulus of the sample were calculated from five independent measurements.

\section{In vitro degradation}

The degradation of non-sterilized and sterilized N-DSC and E/N-DSC was performed using bacterial collagenase from Clostridium histolyticum (EC 3.4.24.3, Sigma Chemical Company, St Louis, MO, USA) with a collagenase activity of $255 \mathrm{Umg}^{-1}$ (one unit will release peptides from native collagen, equivalent in ninhydrin colour to $1.0 \mu \mathrm{mol}$ of L-leucine in $5 \mathrm{~h}$ at $\mathrm{pH} 7.4$ at $37^{\circ} \mathrm{C}$ in the presence of calcium ions). To a DSC sample weighing $10 \mathrm{mg}, 0.5 \mathrm{ml}$ of $0.1 \mathrm{M}$ Tris-HCl buffer ( $\mathrm{pH} 7.4$ ) containing $0.005 \mathrm{M} \mathrm{CaCl}_{2}$ and $0.05 \mathrm{mg} \mathrm{ml}^{-1}$ sodium azide was added. After incubation at $37^{\circ} \mathrm{C}$ for $1 \mathrm{~h}, 0.5 \mathrm{ml}$ collagenase solution (200 $\left.\mathrm{U} \mathrm{ml}^{-1}\right)$ in Tris-HCl buffer $\left(37^{\circ} \mathrm{C}\right)$ was added to give a final collagenase concentration of $100 \mathrm{U} \mathrm{ml}^{-1}$. The absolute amount of collagenase present was $10 \mathrm{Umg}^{-1}$ DSC. During all degradation experiments the $\mathrm{pH}$ of the buffer remained constant. The degradation was discontinued at the desired time interval by the addition of $0.1 \mathrm{ml}$ of $0.25 \mathrm{M}$ ethylenediaminetetra-acetate (Titriplex III p.a., E. Merck, Darmstadt, Germany).

The weight loss of the DSC samples, expressed as the percentage of the initial weight remaining, was related to the hydroxyproline content of the supernatant, which was determined spectrophotometrically ${ }^{14}$. The tensile strength of the samples as a function of degradation time was determined by stress-strain measurements ${ }^{14}$. The change in mechanical properties of a degraded sample was only compared with the mechanical properties of a matching non-degraded control taken from an adjacent part of the skin. Samples used to study the influence of degradation on the mechanical properties were always taken from the IUP $/ 2^{15}$ sampling area, parallel to the backbone, and were either degraded with collagenase or kept as control.

\section{RESULTS}

\section{Initial properties}

The results obtained from the $T_{\mathrm{s}}$ measurements and the free amine group content determinations of the N-DSC and E/N-DSC samples used during the degradation experiments are presented in Table 1. For N-DSC samples, a $T_{s}$ of $56^{\circ} \mathrm{C}$ and a free amine group content of 34.4 per 1000 amino acid residues was measured. The latter value is in good agreement with values reported in the literature ${ }^{16}$. Cross-linking with EDC and NHS increased the $T_{\mathrm{s}}$ to $86^{\circ} \mathrm{C}$ and decreased the free amine group content to 16.3 per 1000 amino acid residues compared to $\mathrm{N}$-DSC samples. Ethylene oxide sterilization of E/N-DSC samples resulted in lower values of $T_{\mathrm{s}}$ and free amine group content compared to non-sterilized E/N-DSC. After ethylene oxide

Table 1 Shrinkage temperature and amine group content of non-cross-linked and cross-linked dermal sheep collagen

\begin{tabular}{|c|c|c|c|}
\hline Sample & Sterilization procedure & Shrinkage temperature $\left({ }^{\circ} \mathrm{C}\right)$ & Amine group content ( $n$ per 1000) \\
\hline $\begin{array}{l}\text { N-DSC* } \\
\text { E/N-DSC }\end{array}$ & $\begin{array}{l}\text { None } \\
\text { None } \\
\text { Ethylene oxide }\end{array}$ & $\begin{array}{l}56.3 \pm 0.3 \\
85.8 \pm 0.3 \\
82.4 \pm 0.4\end{array}$ & $\begin{array}{r}34.4 \pm 0.4 \\
16.3 \pm 0.6 \\
9.5 \pm 0.5\end{array}$ \\
\hline
\end{tabular}

*Non-cross-linked DSC.

${ }^{\dagger} D S C$ cross-linked with EDC and NHS

The free amine group content of DSC is expressed as the number of amine groups present per 1000 amino acids (triplicate measurements) 
sterilization of E/N-DSC, a $T_{\mathrm{s}}$ of $82^{\circ} \mathrm{C}$ and a free amine group content of 9.5 per 1000 amino acid residues was found.

The initial mechanical properties of the N-DSC and E/N-DSC samples used during degradation are presented in Table 2. Ethylene oxide sterilization did not significantly change the tensile strength, elongation at alignment, high strain modulus and elongation at alignmont of the E/N-DSC samples.

\section{In vitro degradation}

To study the in vitro degradation of N-DSC and E/NDSC, samples were exposed to a bacterial collagenase solution. The weight and the tensile strength of the different DSC samples were determined as a function of degradation time. The tensile strength of DSC samples was monitored because it appeared to be more sensitive to degradation than the high strain modulus or the elongation at break ${ }^{14}$. The extent of degradation is expressed as percentage decrease in the original value of weight and tensile strength, respectively. Because partially degraded N-DSC behaved like denatured collagen, no cross-sectional area of the test specimens could be measured and consequently the tensile strength could not be determined. Therefore, the progress of degradation of N-DSC is represented by a dotted line from the start of degradation to the time at which the DSC samples desintegrated, when the degradation tube was vigorously shaken.

The percentage weight loss of N-DSC and E/N-DSC as a function of degradation time is presented in Figure 1a. The rate of weight loss was determined from the initial slope of the lines presented in Figure 1a. For NDSC a rate of weight loss of $18 \%$ per hour was found. For E/N-DSC no weight loss was observed during a $24 \mathrm{~h}$ degradation period.

The degradation behaviour as a function of degree of cross-linking was determined using a series of $\mathrm{E} / \mathrm{N}$ DSC samples with increasing $T_{\mathrm{s}}$ values. Samples with $T_{\mathrm{s}}$ values of $66,77,83$ and $86^{\circ} \mathrm{C}$ were obtained by cross-linking N-DSC samples using molar ratios of EDC to NHS to COOH of 0.2:0.08:1, 0.5:0.2:1, 1:0.4:1 and $5: 2: 1$, respectively. The change in weight of these samples as a function of degradation time is shown in Figure 1a. The rate of weight loss decreases with an increasing degree of cross-linking of the samples. For samples with a $T_{\mathrm{s}}$ of $56,66,77$ and $83^{\circ} \mathrm{C}$, a rate of weight loss of $18.1,2.7,0.7$ and $0.05 \%$ per hour, respectively, was found

The changes in tensile strength during degradation of N-DSC and E/N-DSC samples are presented in Figure
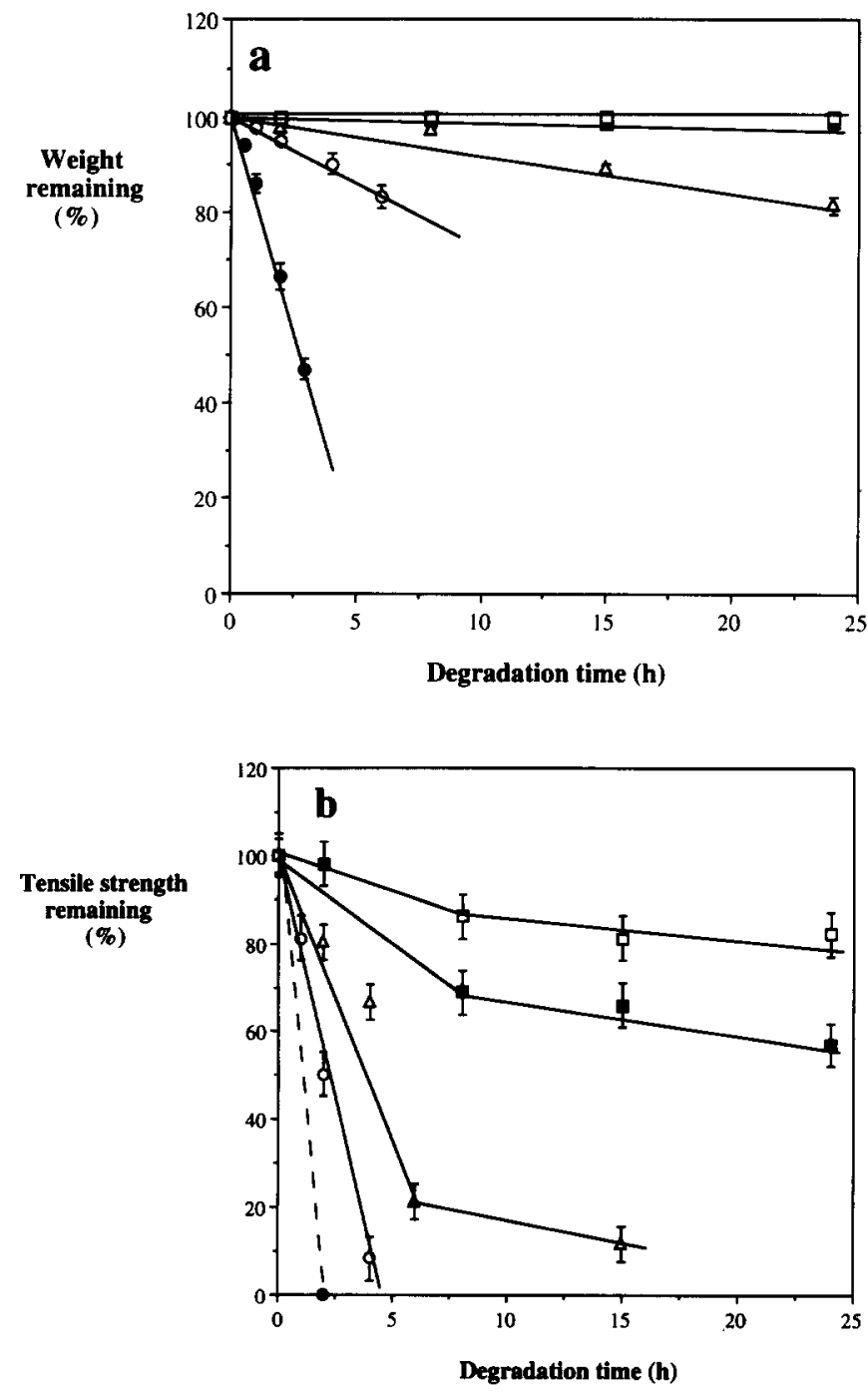

Flgure 1 Changes in: $\mathbf{a}$, weight and, $\mathbf{b}$, in tensile strength as a function of degradation time during exposure of $\mathrm{N}$ DSC with a $T_{\mathrm{s}}$ of $56^{\circ} \mathrm{C}(\mathbf{C})$, and E/N-DSC with a $T_{\mathrm{s}}$ of $66^{\circ} \mathrm{C}$ (O), $77^{\circ} \mathrm{C}(\triangle), 83^{\circ} \mathrm{C}(\square)$ and $86^{\circ} \mathrm{C}(\square)$ to a bacterial collagenase solution ( $\mathrm{pH} 7.4,37^{\circ} \mathrm{C}, n=5$, \pm s.d.).

1b. N-DSC samples were most susceptible to degradation and had no tensile strength remaining after a $2 \mathrm{~h}$ degradation period. E/N-DSC samples with a high $T_{s}$ showed a slow decrease in tensile strength. The tensile strength of partially degraded E/N-DSC samples with the highest degree of cross-linking $\left(86^{\circ} \mathrm{C}\right)$ was $82 \%$ of the initial value after a $24 \mathrm{~h}$ cross-linking period.

Table 2 Mechanical properties of non-cross-linked and cross-linked dermal sheep collagen

\begin{tabular}{|c|c|c|c|c|c|c|}
\hline Sample & $\begin{array}{l}\text { Sterilization } \\
\text { procedure }\end{array}$ & $\begin{array}{l}\text { Tensile } \\
\text { strength } \\
\text { (MPa) }\end{array}$ & $\begin{array}{l}\text { Elongation } \\
\text { at alignment } \\
(\%)\end{array}$ & $\begin{array}{l}\text { Elongation } \\
\text { at break } \\
(\%)\end{array}$ & $\begin{array}{l}\text { Low strain } \\
\text { modulus } \\
\text { (MPa) }\end{array}$ & $\begin{array}{l}\text { High strain } \\
\text { modulus } \\
\text { (MPa) }\end{array}$ \\
\hline $\begin{array}{l}\text { N-DSC* } \\
\text { E/N-DSC }\end{array}$ & $\begin{array}{l}\text { None } \\
\text { None } \\
\text { Ethylene oxide }\end{array}$ & $\begin{array}{l}16 \pm 1 \\
11 \pm 1 \\
10 \pm 1\end{array}$ & $\begin{array}{l}67 \pm 7 \\
76 \pm 5 \\
69 \pm 6\end{array}$ & $\begin{array}{l}167 \pm 5 \\
186 \pm 11 \\
171 \pm 9\end{array}$ & $\begin{array}{l}1.8 \pm 0.1 \\
3.4 \pm 0.3 \\
3.8 \pm 0.2\end{array}$ & $\begin{array}{r}17 \pm 2 \\
8 \pm 1 \\
8 \pm 1\end{array}$ \\
\hline
\end{tabular}

Non-cross-linked DSC.

${ }^{\dagger}$ DSC cross-linked with EDC and NHS

All mechanical properties are given as mean \pm s.d. of five measurements 
The influence of ethylene oxide sterilization on the change in weight and tensile strength during degradation of E/N-DSC samples is shown in Figure $2 a$ and $b$, respectively. For both non-sterilized E/N-DSC and ethylene oxide-sterilized E/N-DSC, no weight loss was found during a $24 \mathrm{~h}$ degradation period (Figure 2a). During this period a slight decrease in tensile strength was observed for non-sterilized E/N-DSC (Figure 2b). Contrary to non-sterilized E/N-DSC, no loss in tensile strength was observed for the ethylene oxide-sterilized E/N-DSC samples during a $24 \mathrm{~h}$ degradation period.

\section{DISCUSSION}

Collagen-based biomaterials are generally stabilized by chemical cross-linking before in vivo application. In a previous paper we reported on the use of a mixture of the water-soluble carbodiimide EDC and NHS for the cross-linking of $\mathrm{DSC}^{10}$. Cross-linking using EDC and NHS involves the activation of carboxylic acid groups
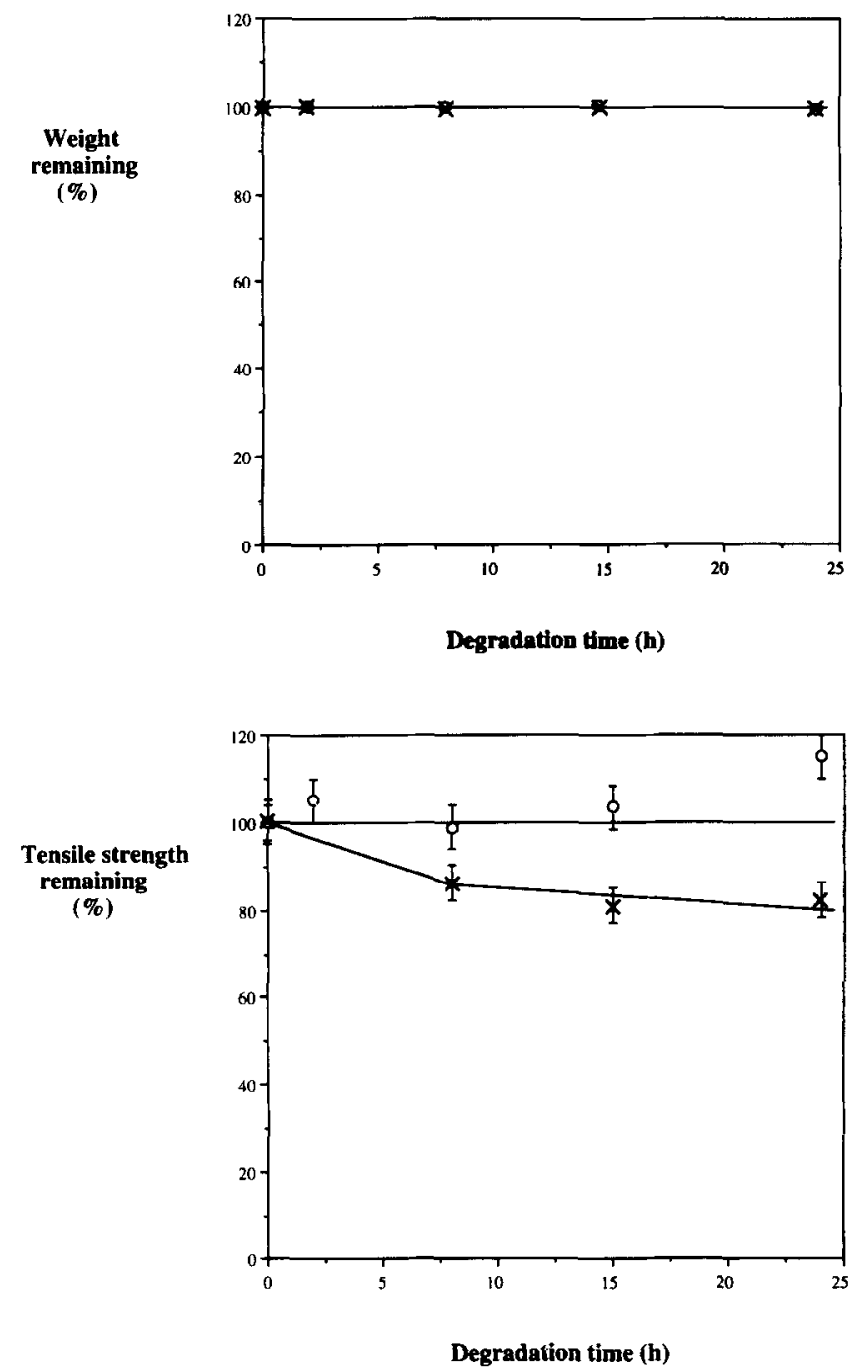

Figure 2 Changes in: a, weight and, $\mathbf{b}$, in tensile strength as a function of degradation time during exposure of nonsterilized E/N-DSC $(x)$ and ethylene oxide-sterilized E/NDSC $(O)$ to a bacterial collagenase solution $\left(\mathrm{pH} 7.4,37^{\circ} \mathrm{C}\right.$, $n=5, \pm$ s.d.). of polypeptide chains to give NHS-activated carboxylic acid groups which form cross-links after reaction with free amine groups of other polypeptide chains. The results obtained revealed that treatment of N-DSC with $\mathrm{E} / \mathrm{N}$-DSC increased the $T_{\mathrm{s}}$ value from $56^{\circ}$ for N-DSC to $86^{\circ}$ for E/N-DSC samples ${ }^{10}$. In contrast, treatment of $\mathrm{N}$ DSC with glutaraldehyde only increased the $T_{\mathrm{s}}$ from 56 to $78^{\circ} \mathrm{C}^{1}$.

Recently, the in vitro degradation of glutaraldehyde cross-linked DSC samples (G-DSC) has been described $^{14}$. Exposure of G-DSC samples to bacterial collagenase resulted in a weight loss of $3.5 \%$ after a $24 \mathrm{~h}$ degradation period (rate of weight loss $0.14 \%$ per hour). During this period, an initially fast decrease in tensile strength was observed. After an $8 \mathrm{~h}$ degradation period, the partially degraded G-DSC samples had only $35 \%$ of their initial tensile strength remaining. Longer degradation times resulted in partially degraded samples having only $25 \%$ of their initial tensile strength remaining after a $24 \mathrm{~h}$ degradation period. The degradation of E/N-DSC samples was performed applying identical conditions as used during the degradation of the G-DSC samples.

The influence of ethylene oxide gas treatment on the degradation behaviour of E/N-DSC samples was determined because this method has previously been selected as the preferred method for the sterilization of collagen-based biomaterials ${ }^{11}$. Bacterial collagenase is capable of cleaving peptide bonds within the triple helical structure of collagen and has a specificity for the Pro-X-Gly-Pro-Y region, splitting between $X$ and $\mathrm{Gly}^{17,18}$. It has been shown that enzymatic degradation of polyesters occurs by a surface erosion process which is experimentally characterized by a zero order weight loss in the initial stage of the degradation ${ }^{19,20}$. A zero order weight loss was always observed for the degradation of either non-cross-linked or cross-linked DSC. This suggests that the degradation of DSC can be depicted as a surface erosion process, as was described previously for reconstituted collagen ${ }^{21}$.

Cross-linking of DSC using a mixture of EDC and NHS gave materials with a $T_{\mathrm{s}}$ of $86^{\circ} \mathrm{C}$ (Table 1). The high degree of cross-linking of E/N-DSC samples is reflected in their resistance towards enzymatic degradation using bacterial collagenase. Both the decrease in weight (Figure 1a) and the decrease in tensile strength (Figure $1 b$ ) in time were significantly slower compared with N-DSC. It appeared that both the rate of weight loss and the decrease in tensile strength during degradation were controlled by the degree of cross-linking of the samples.

The decreased rate of weight loss of cross-linked versus non-cross-linked DSC samples during enzymatic degradation is most probably owing to interference of the penetration of the enzyme into the fibre $^{1}$. The reduced penetration will substantially decrease the surface area available for adsorption of the enzyme in the cross-linked collagen network and thus the surface degradation rate. Moreover, owing to the introduction of cross-links, on average more chains have to be cleaved before a degraded fragment can be solubilized.

These considerations can also be applied to describe the influence of cross-linking on the change in tensile 


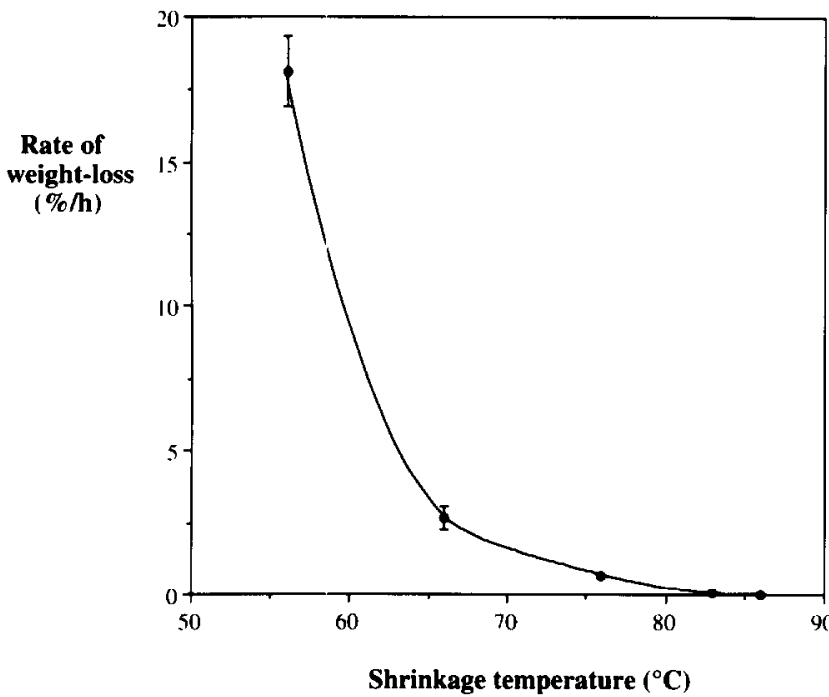

Figure 3 Rate of weight loss as a function of shrinkage temperature for E/N-DSC samples.

strength during degradation. If cross-linking prevents the penetration of the enzyme in the fibre structure and erosion occurs only at the fibre surface, the loadbearing area of the material will decrease more slowly for materials with a higher degree of cross-linking. Furthermore, cross-links present in the cross-linked materials will retain the strength of the samples for a longer period during degradation.

The rate of weight loss of E/N-DSC samples as a function of the $T_{\mathrm{s}}$ value is shown in Figure 3. This figure is constructed from the data presented in Figure 1a. It appears that two phases can be distinguished in this plot. At low degrees of cross-linking $\left(T_{\mathrm{s}}\right.$ values up to $66^{\circ} \mathrm{C}$ ), a small increase in $T_{s}$ results in a large decrease in rate of weight luss. As a result of crosslinking between fibrils the penetration of the enzyme into the fibres is hindered. This will reduce the surface area available for adsorption of collagenase and will have a large influence on the degradation rate. At higher degrees of cross-linking $\left(T_{\mathrm{s}}\right.$ values of $66^{\circ} \mathrm{C}$ and higher), a further increase in $T_{\mathrm{s}}$ only results in small changes in the rate of weight loss. The decreased rate of weight loss is probably based on the reduction of the rate of solubilization of degraded parts from the fibre surface.

When the degradation behaviour of E/N-DSC samples is compared with the previously reported degradation behaviour of G-DSC samples ${ }^{14}$, it is observed that E/NDSC samples are more resistant towards in vitro degradation by bacterial collagenase. Contrary to GDSC, no weight loss is observed during a $24 \mathrm{~h}$ degradation period for the E/N-DSC samples and only a gradual decrease in tensile strength during degradation is found, resulting in partially degraded samples having $82 \%$ of the initial tensile strength remaining after $24 \mathrm{~h}$ degradation.

Ethylene oxide gas sterilization improves the resistance of non-cross-linked and cross-linked DSC samples towards enzymatic degradation ${ }^{11}$. During sterilization, ethylene oxide molecules react with the free amine groups of DSC. The $N$-2-hydroxyethyl groups may interfere with the adsorption of the enzyme, thus decreasing the rate of degradation. Similar results were obtained in this study. In Table 1 a decrease in free amine group content is observed for ethylene oxide-sterilized E/N-DSC samples compared with non-sterilized samples, showing that reaction of ethylene oxide with amine groups occurred during ethylene oxide sterilization. The reaction of ethylene oxide with the free amine groups did not significantly change the mechanical properties of E/N-DSC (Table 2). No significant differenres in weight loss were observed between non-sterilized and ethylene oxidesterilized E/N-DSC samples during a $24 \mathrm{~h}$ degradation period (Figure 2a). However, a significant increase in resistance to degradation was observed when the tensile strength of the samples was monitored as a function of degradation time (Figure 2b). Contrary to non-sterilized E/N-DSC, the tensile strength of the ethylene oxide-sterilized E/N-DSC samples was not affected by exposure to bacterial collagenease for $24 \mathrm{~h}$, indicating that ethylene oxide-sterilized E/N-DSC samples were more resistant to degradation.

\section{CONCLUSIONS}

The resistance against degradation by bacterial collagenase of E/N-DSC samples was increased compared to N-DSC. The susceptibility of E/N-DSC samples towards enzymatic degradation could be controlled by varying the degree of cross-linking of the samples. During ethylene oxide gas sterilization of the E/N-DSC samples, reaction of ethylene oxide with the free amine groups of E/N-DSC occurred. Ethylene oxide-sterilized E/N-DSC samples had an improved resistance to degradation resulting from an interference of the $N$-2-hydroxyethyl groups with the adsorption sites for bacterial collagenase.

\section{REFERENCES}

1 Olde Damink LHH, Dijkstra PJ, van Luyn MJA, van Wachem PB, Nieuwenhuis P, Feijen J. Glutaraldehyde as a crosslinking agent for collagen-based biomaterials. J Mater Sci: Mater Med 1995; 6: 460-472.

2 Olde Damink LHH, Dijkstra PJ, van Luyn MJA, van Wachem PB, Nieuwenhuis P, Feijen J. Crosslinking of dermal sheep collagen using hexamethylene diisocyanate. J Mater Sci: Mater Med 1995; 6: 429-434.

3 van Luyn MJA, van Wachem PB, Olde Damink LHH, Dijkstra PJ, Feijen J, Nieuwenhuis P. Methylcellulose cell culture: a new cytotoxicity test system for biomaterials. J Mater Sci: Mater Med 1992; 2: 142-148.

4 van Luyn MJA, van Wachem PB, Olde Damink LHH, Dijkstra PJ, Feijen J, Nieuwenhuis P. Relations between in vilro cytutoxicity and crosslinking of collagen. $f$ Biomed Mater Res 1992; 26: 1091-1010.

5 van Luyn MJA, van Wachem PB, Olde Damink LHH, Dijkstra PJ, Feijen J, Nieuwenhuis P. Secondary cytotoxicity of (crosslinked) dermal sheep collagen during repeated exposure to human fibroblasts. Biomaterials 1992; 13: 1027-1024.

6 van Wachem PB, van Luyn MJA, Olde Damink LHH, Feijen J, Nieuwenhuis $\mathrm{P}$. Tissue interactions with dermal sheep collagen implants: a transmission 
electron microscopical evaluation. Cells Mater 1992; 1: 251-263.

7 van Wachem $P B$, van Luyn MJA, Nieuwenhuis $P$, Koerten HK, Olde Damink LHH, Feijen J. In vivo degradation of processed dermal sheep collagen evaluated with transmission electron microscopy. Biomaterials 1991; 12: 215-223.

8 Tu R, Shen S-H, Lin D et al. Fixation of bioprosthetic tissues with monofunctional and multifunctional polyepoxy compounds. J Biomed Mater Res 1994; 28: 677-684.

9 Tu R, Quijano C, Lu CL et al. A preliminary study of the fixation mechanism of collagen reaction with a polyepoxy fixative. Int J Artif Organs 1993; 7: 537-544.

10 Olde Damink LHH, Dijkstra PJ, van Luyn MJA, van Wachem PB, Nieuwenhuis P, Feijen J. Cross-linking of dermal sheep collagen using a water-soluble carbodiimide. Biomaterials 1995; in press.

11 Olde Damink LHH, Dijkstra PJ, van Luyn MJA, van Wachem PB, Nieuwenhuis P, Feijen J. Influence of ethylene oxide gas treatment on the in vitro degradation behaviour of dermal sheep collagen. I Biomed Mater Res 1995; 29: 149-157.

12 van Gulik TM, Klopper PJ. The processing of sheepskin for use as a dermal collagen graft - an experimental study. Neth J Surg 1987; 39: 90-94.

13 Flory PJ, Garrett RR. Phase transitions in collagen and gelatin systems. J Am Chem Soc 1958; 80: 4836-4845.
Olde Damink LHH, Dijkstra PJ, van Luyn MJA, van Wachem PB, Nieuwenhuis P, Feijen J. Changes in the mechanical properties of dermal sheep collagen during in vitro degradation. $J$ Biomed Mater Res 1995; 29: 139-149.

15 Society of Leather Trades Chemists. Sampling IUP/2. I Soc Lether Trades Chemists 1958; 42: 382.

16 Nedkov P, Glanville R, Goshev I, Kühn K. Isolierung and teilweise Charakterisierung von Schafshautkollagen, in Lösung gebracht mit Hilfe von Subtilisin DY. Das Leder 1983; 34: 54-58.

17 Wünsch E, Heindrich HG. Zur quantitativen bestimmung der Kollagenase. J. Physiol Chem 1963; 333: 149-151.

18 Harper E, Berger A, Katchalski E. The hydrolysis of poly(L-prolyl-glycyl-L-prolyl) by bacterial collagenase. Biopolymers 1972; 11: 1607-1612.

19 Doi Y, Kanesawa Y, Kunioka M, Saito T. Biodegradation of microbial copolyesters: poly(3hydroxybutyrate-co-hydroxyvalerate) and poly(3hydroxybutyrate-co-4-hydroxybutyrate). Macromolecules 1990; 23: 26-31.

20 Pitt CG, Hendren RW, Schindler A, Woodward SC. The enzymatic surface erosion of aliphatic polyesters. I Contr Rel 1984; 1: 3-14.

21 Steven FS. Polymeric collagen fibrils: an example of substrate-mediated steric obstruction of enzymic digestion. Biochim Biophys Acta 1976; 452: 151-160. 